Bull. Mater. Sci., Vol. 36, No. 5, October 2013, pp. 807-812. (C) Indian Academy of Sciences.

\title{
Thickness effect on properties of titanium film deposited by d.c. magnetron sputtering and electron beam evaporation techniques
}

\author{
NISHAT ARSHI, JUNQING LU*, CHAN GYU LEE, JAE HONG YOON, BON HEUN KOO \\ and FAHEEM AHMED \\ School of Nano \& Advanced Materials Engineering, Changwon National University, Changwon, Gyeongnam 641-773, \\ Republic of Korea
}

MS received 25 March 2012; revised 1 August 2012

\begin{abstract}
This paper reports effect of thickness on the properties of titanium ( $\mathrm{Ti})$ film deposited on $\mathrm{Si}_{/} \mathrm{SiO}_{2}(100)$ substrate using two different methods: d.c. magnetron sputtering and electron beam (e-beam) evaporation technique. The structural and morphological characterization of Ti film were performed using X-ray diffraction (XRD), X-ray photoelectron spectroscopy (XPS), field emission scanning electron microscopy (FESEM) and atomic force microscopy (AFM). XRD pattern revealed that the films deposited using d.c. magnetron sputtering have HCP symmetry with preferred orientation along $(002)$ plane, while those deposited with e-beam evaporation possessed fcc symmetry with preferred orientation along (200) plane. The presence of metallic Ti was also confirmed by XPS analysis. FESEM images depicted that the finite sized grains were uniformly distributed on the surface and AFM micrographs revealed roughness of the film. The electrical resistivity measured using four-point probe showed that the film deposited using d.c. magnetron sputtering has lower resistivity of $\sim 13 \mu \Omega \mathrm{cm}$ than the film deposited using e-beam evaporation technique, i.e. $\sim 60 \mu \Omega \mathrm{cm}$. The hardness of Ti films deposited using d.c. magnetron sputtering has lower value ( 7.9 GPa) than the film deposited using e-beam technique ( 9.4 GPa).
\end{abstract}

Keywords. Thin films; atomic force microscopy (AFM); surfaces; hardness; X-ray diffraction; electron microscopy.

\section{Introduction}

For many decades, titanium (Ti) films have been extensively studied for their applications in various fields especially in aerospace and microelectronics and their diffusion barrier properties due to their high mechanical strength, excellent chemical and thermal stabilities and good corrosion resistance (Wayman 1992; Boyer 1996; Benard et al 1998; Wei et al 1998; Hyun et al 2004; Jeyachandran et al 2006; Resnik et al 2008). A lot of work has been done so far in order to deposit Ti film using physical vapour deposition (PVD) technique (Bunshah and Juntz 1973), RF magnetron sputtering (Martin et al 1998), pulsed magnetron sputtering (Henderson et al 2003), ion beam sputtering technique (Muraishi et al 2004) and d.c. magnetron sputtering (Jeyachandran et al 2007a, b). The properties of Ti films deposited by PVD techniques depend strongly on structural characteristics such as grain morphology, textures and porosity. The influence of various process parameters such as substrate temperature, pressure and power on the morphological features of $\mathrm{Ti}$ films needs to be understood in order to use it for its superior performance and reliability in the actual device applications (Cai et al 2005). Naoe et al (1991) showed effect of various sputtering conditions such as the argon pressure,

\footnotetext{
*Author for correspondence (junqinglu@yahoo.com)
}

substrate temperature and bias voltage on Ti films and reported that the surface morphology of Ti films changed from fine particle structure to that of fine fibres with increase in substrate temperature. Cai et al (2005) deposited Ti film using e-beam evaporation technique on glass substrate and showed a linear relationship between surface roughness and evaporation rate. The microstructural characteristics such as grain size, morphology, density and textures of the grains strongly depend on the deposition technique. Therefore, it is important to understand influence of the deposition process on the properties of titanium film to further enhance their properties in actual applications. Various groups have reported effect of thickness on the properties of Ti film deposited using a single deposition technique (Cai et al 2005; Jeyachandran et al 2007a, b; Song et al 2007; Chakraborty et al 2011).

However, here, even if we assume that Ti films of different thickness are deposited using two different PVD (d.c. sputtering and e-beam evaporation) techniques, effect of thickness on properties of the films remains the same as reported in earlier reports. Therefore, the purpose of the present work is to study the effect of thickness on the properties of $\mathrm{Ti}$ film deposited on $\mathrm{Si} / \mathrm{SiO}_{2}$ (100) substrate using d.c. sputtering and e-beam evaporation techniques. The as-deposited Ti films were characterized by XRD, XPS, FESEM and AFM techniques. The electrical properties were analysed by fourpoint probe method and mechanical property was studied by Vickers microhardness tester. 


\section{Experimental}

$\mathrm{Ti}$ (99.9999\%, 3.175 mm diameter $\times 3.175 \mathrm{~mm}$ length) and $\mathrm{Ti}$ (of $99.99 \%$ pure, $100 \mathrm{~mm}$ diameter and $5 \mathrm{~mm}$ thickness) were purchased from Alfa Aesar as e-beam and sputtering target, respectively. The films were deposited on $\mathrm{Si} / \mathrm{SiO}_{2}$ (100) substrate $\left(\right.$ area $=40 \times 20 \mathrm{~mm}^{2}$ ) which was oxidized in a furnace for $1 \mathrm{~h}$ at $1000{ }^{\circ} \mathrm{C}$ and cleaned by rinsing in ultrasonic baths of acetone and methanol prior to deposition. The substrates were clamped to the substrate holder and the distance between the target and the substrate was maintained. Ti film deposited by e-beam has an operating pressure of about $1.3 \times 10^{-6}$ Torr with a substrate temperature of $200{ }^{\circ} \mathrm{C}$ and the power level was fixed at $500 \mathrm{~W}$. Whereas, the film deposited using d.c. magnetron sputtering has an operating pressure of about $5 \times 10^{-6}$ Torr with the power level fixed at $360 \mathrm{~W}$. The substrate temperature was kept same as in the case of e-beam technique. Argon gas flow of $10 \mathrm{sccm}$ was introduced as a sputtering gas. Before deposition, the substrate was pre-sputtered in argon gas for $5 \mathrm{~min}$. Both the films were deposited for $30 \mathrm{~min}$ with deposition rate of $\sim 0.11 \mathrm{~nm} / \mathrm{s}$ and $0.27 \mathrm{~nm} / \mathrm{s}$ for e-beam evaporated and sputtered film, respectively.

The phase purity of the as-deposited film was characterized using X'pert MPD 3040 X-ray diffractometer (XRD) with $\operatorname{CuK} \alpha(\lambda=1.541 \AA)$ radiation operated at $40 \mathrm{kV}$ and current of $30 \mathrm{~mA}$. The chemical and phase compositions of different Ti films were determined by XPS, using an ESCALAB 250 XPS, VG-scientific sigma probe spectrometer employing a monochromated $\mathrm{Al}-\mathrm{K} \alpha$ source and a hemispherical analyser. A pass energy/step of $50 / 0 \cdot 1 \mathrm{eV}$ was used for narrow scans. Prior to analysis, samples were etched using a $3 \mathrm{keV}$ argon ion beam, until the oxygen $1 \mathrm{~s}$ peak reached a stable minimum value. The morphology and thickness of the as-deposited Ti film were observed by field emission scanning electron microscopy (FESEM, TESCAN, MIRA II LMH). The compositional analysis of the films was done using energy dispersive X-ray spectroscopy (EDS) attached to FESEM. AFM characterization of the Ti film was obtained with Veeco, Digital Instruments, Innova in tapping mode under ambient condition at room temperature. A $5 \times$ $5 \mu \mathrm{m}^{2}$ scanner and an etched silicon nitride tip attached to a cantilever with a spring constant of $0.9 \mathrm{Nm}^{-1}$ were used. The hardness of Ti film was analysed by Vickers hardness tester. The loading and unloading phases of indentation were carried out over a time span of $\sim 10 \mathrm{~s}$ throughout the experiment and five indents were made for each specimen. The resistivity of the as-deposited Ti film was measured by four-point probe (MCP-T600) method at room temperature.

\section{Results and discussion}

Figure 1 shows X-ray diffraction pattern of Ti films deposited by e-beam evaporation and d.c. magnetron sputtering techniques. It is clear from figure 1 that the film deposited by e-beam shows typical peaks attributed to (111) and (200)

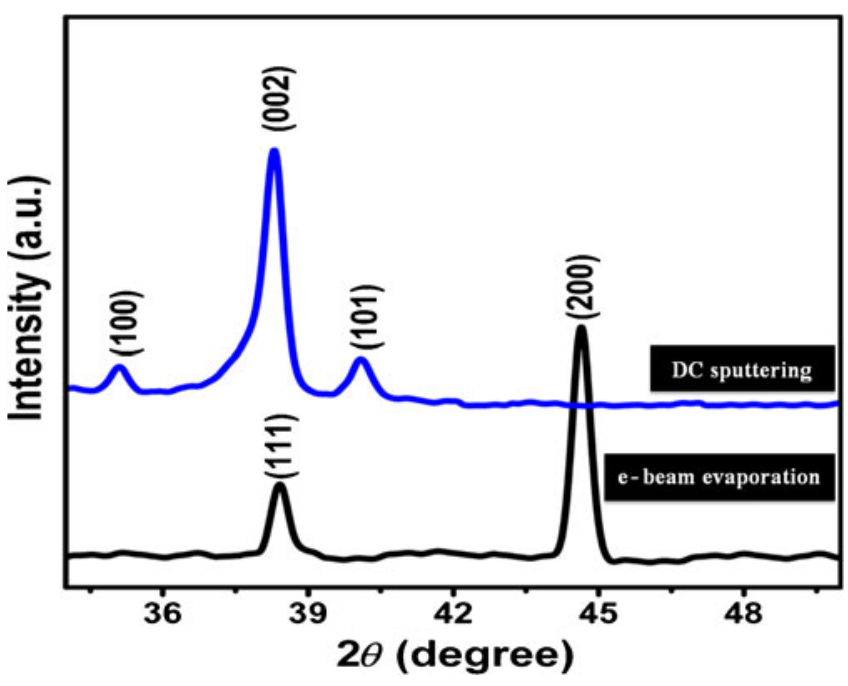

Figure 1. XRD pattern of $\mathrm{Ti}$ films deposited on $\mathrm{Si} / \mathrm{SiO}_{2}$ substrate.

planes, having preferred orientation along (200) plane for single phase face centred cubic (fcc) structure. However, for d.c. sputtered Ti film, the peaks are attributed to (100), (002) and (101) planes having preferred orientation along (002) plane for single phase hexagonal close packed (hcp) structure. It is well known that $\mathrm{Ti}$ has a cubic or a hexagonal structure (Scardi et al 1998). Thus XRD pattern revealed the fcc structure for film deposited with e-beam and hop structure for the films deposited with d.c. sputtering. The observation of fcc Ti phase has also been reported in bulk Ti powders during mechanical milling of Ti (Manna et al 2003) and also ultrathin (2-50 nm thickness) epitaxial films (Kim et al 1996; Salch et al 1997) on various substrates. Recently, Chakraborty et al (2011) showed that fcc symmetry is stable for thin Ti films. Moreover, hep structure of Ti using d.c. sputtering has been shown in various reports (Song et al 2007; Chawla et al 2009). Therefore, the observed fcc and hcp structures in the present work are in good agreement with the earlier reports (Kim et al 1996; Salch et al 1997; Manna et al 2003; Chakraborty et al 2011). The refined value of lattice parameters were found to be $a=4.055 \AA$ (JCPDS card-882321) for fcc and $a=2.950 \AA, c=4.681 \AA$ (JCPDS card-65-6321) for hcp Ti films, respectively. Also, no evidence for $\mathrm{TiO}_{2}$, a common titanium oxide on the surface of titanium, was found within the detection limit of XRD. In order to determine the degree of preferred orientation, texture coefficient was calculated using the formula (Kajikawa et al 2002):

Texture coefficient $\left(T_{\mathrm{c}}\right)$

$$
=\frac{I\left(h_{i} k_{i} l_{i}\right)}{I\left(h_{i} k_{i} l_{i}\right)+I\left(h_{j} k_{j} l_{j}\right)+I\left(h_{m} k_{m} l_{m}\right)},
$$

where $h k l$ represents (111), (200), (100), (002) and (101) orientations. Figure 2 shows texture coefficients of Ti films 


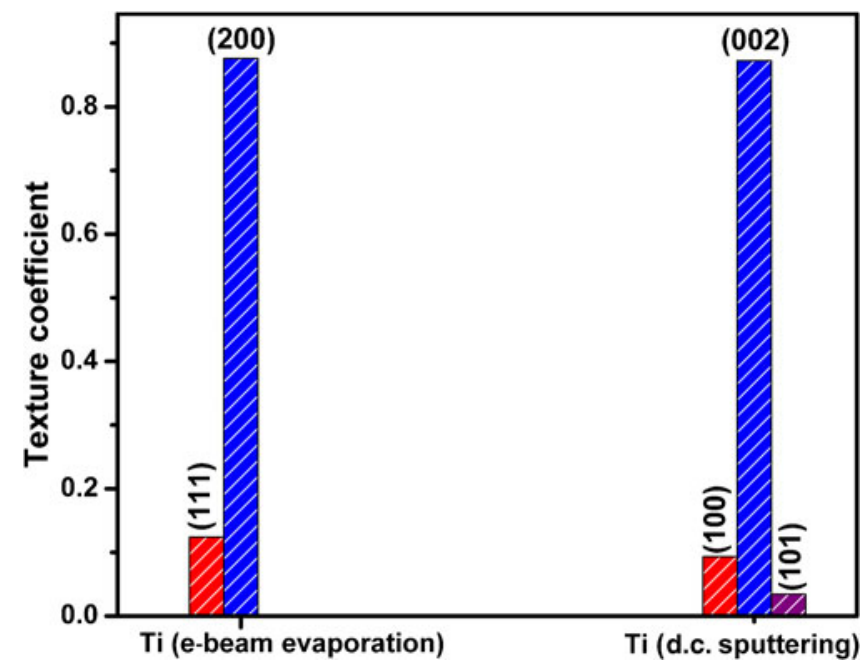

Figure 2. Texture coefficients of Ti films deposited on $\mathrm{Si} / \mathrm{SiO}_{2}$ substrate.

calculated from their respective XRD peaks by using (1). The film deposited by e-beam evaporation is textured along (200) plane for fcc structure, whereas the one deposited by d.c. magnetron indicated strong (002) preferred orientation with hcp structure. This difference in the crystal structure is due to the difference in their deposition rates. The deposition rate for e-beam evaporated and sputtered films are $\sim 0.11 \mathrm{~nm} / \mathrm{s}$ and $0.27 \mathrm{~nm} / \mathrm{s}$, respectively. It was observed in the earlier report (Chakraborty et al 2011) that the fcc symmetry is stable over thin Ti films. In the present work, low deposition rate $(\sim 0.11 \mathrm{~nm} / \mathrm{s})$ for e-beam deposited film will yield a thin Ti film, resulting in fcc symmetry, whereas, high deposition rate $(0.27 \mathrm{~nm} / \mathrm{s})$ for d.c. sputtered film will have hcp symmetry due to more thickness of the film. These findings are in good agreement with the results reported by several researchers (Chakraborty et al 2011). The grain size of the film was calculated using the Scherrer formula (Warren 1969):

$$
D=0.9 \lambda / B \cos \theta,
$$

where $\lambda$ is the wavelength of the incident $\mathrm{CuK} \alpha \mathrm{X}$-rays $(1.514 \AA), B$ the full width at half maxima (FWHM) of the diffraction peak and $\theta$ the diffraction angle. The grain size of the as-deposited Ti was found to be $\sim 25 \mathrm{~nm}$ and $\sim 80 \mathrm{~nm}$ for e-beam and sputter deposited film, respectively. This difference in grain size is also due to the difference in the deposition rates of the deposited films as discussed above.

XPS is a sensitive surface analysis technique, which is capable of providing both qualitative and quantitative information about the presence of different elements at the surface. Figure 3 shows high-resolution XPS-spectrum of Ti films prepared by e-beam evaporation and d.c. sputtering, respectively. After peak fitting treatment (see figure 4), it is clear that the doublet peaks in the spectrum are attributed to metallic Ti, corresponding with Ti $2 p_{3 / 2}$ at a binding energy (BE) of $453.9 \mathrm{eV}$ and Ti $2 p_{1 / 2}$ at BE of $460 \mathrm{eV}$. These values of binding energies for metallic $\mathrm{Ti}$ are in good agreement

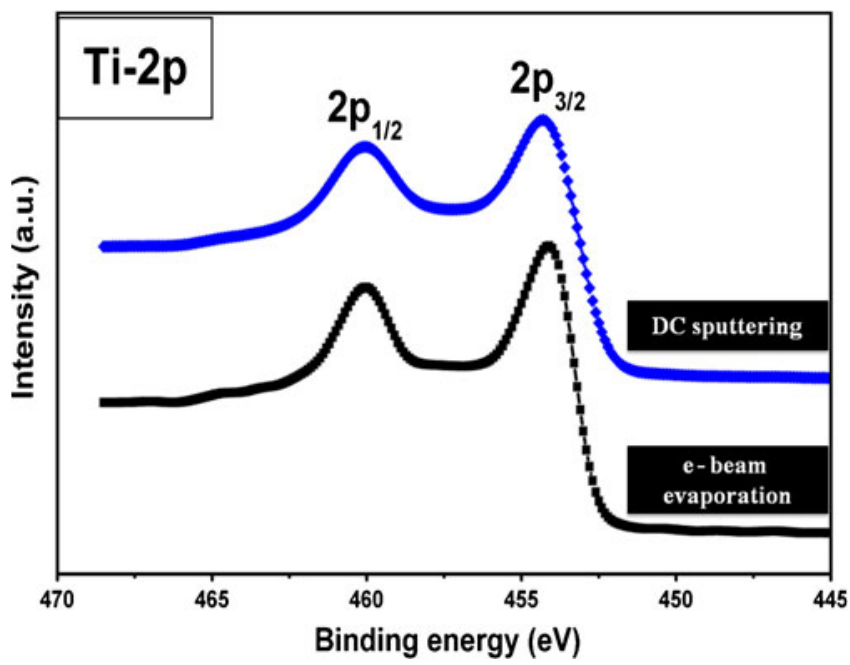

Figure 3. XPS-Ti $2 p$ spectra for deposited Ti films.

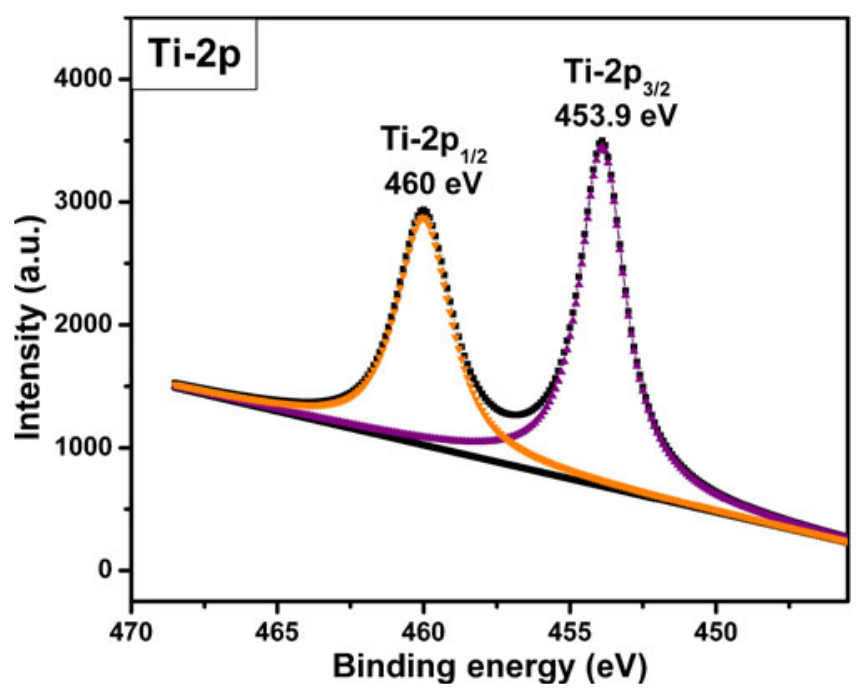

Figure 4. Deconvoluted XPS-Ti $2 p$ spectra for Ti films deposited using e-beam evaporation technique.

with several reports (Galvanettoa et al 2001; Jeyachandran et al 2007a, b). The other Ti $2 p$ peak for different phases, i.e. titanium nitrides, oxides, oxynitrides and carbides, with binding energies at 454.8, 458, 456 and $455 \mathrm{eV}$, respectively (Galvanettoa et al 2001) cannot be resolved in the collected spectra. This implies the absence of any secondary phase on the surface of the film. These results obtained from XPS are in good agreement with XRD data.

Figure 5( $\mathrm{a}$ and $\mathrm{b})$ shows FESEM images of $\mathrm{Ti}$ film deposited using e-beam and d.c. sputtering techniques, respectively and figure 5(c and d) shows corresponding EDX spectra. It is clear from figure 5(a) that the finite size grains are uniformly distributed on the surface of the film. However, figure 5(b) reveals the presence of large grain size on surface of the film. The chemical composition in figure 5(c and d), deduced from EDX measurements, shows major peaks for 


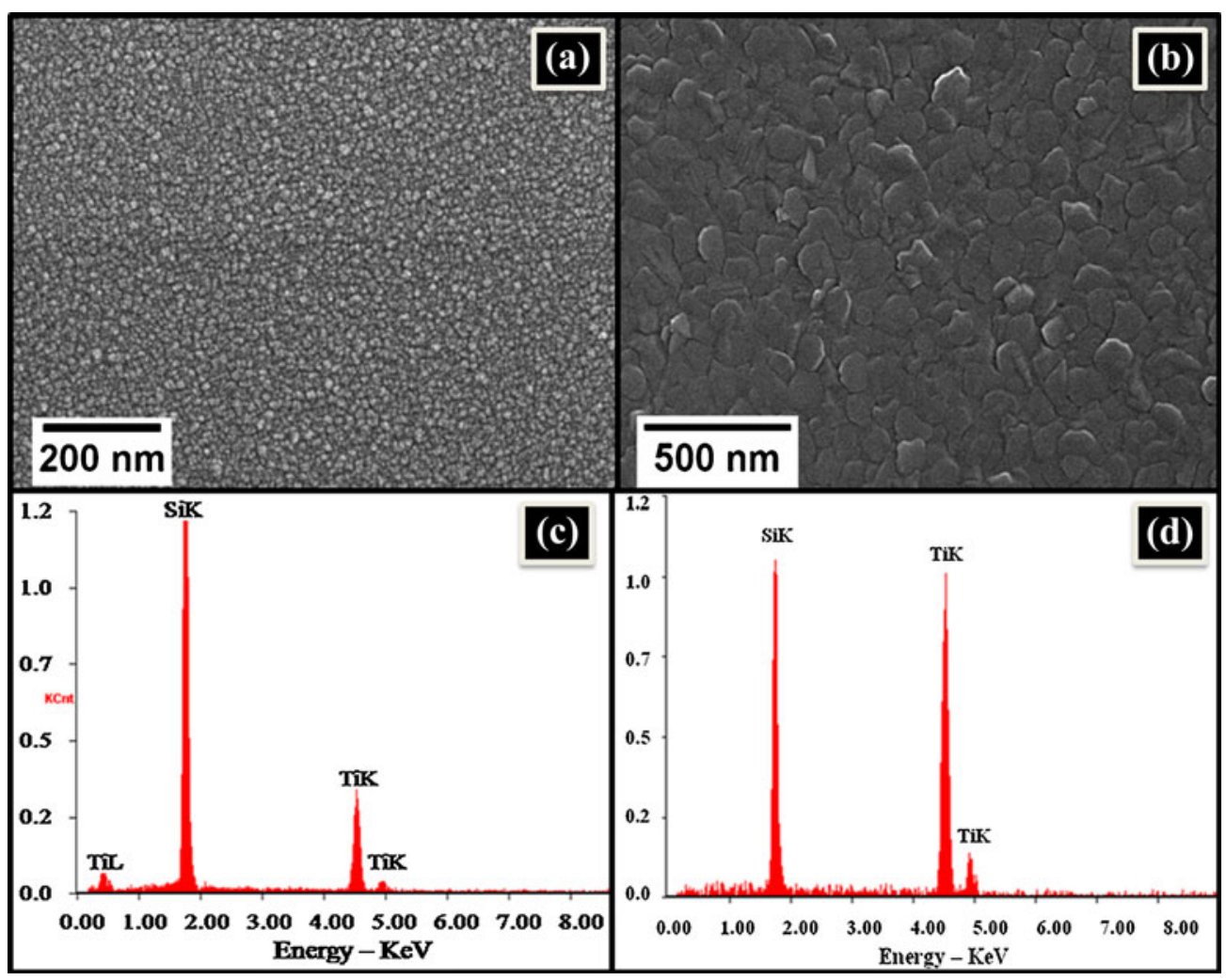

Figure 5. (a) FESEM images and (c) corresponding EDX spectra for e-beam evaporated and (b) FESEM images and (d) corresponding EDX spectra for d.c. sputtered Ti films, respectively.

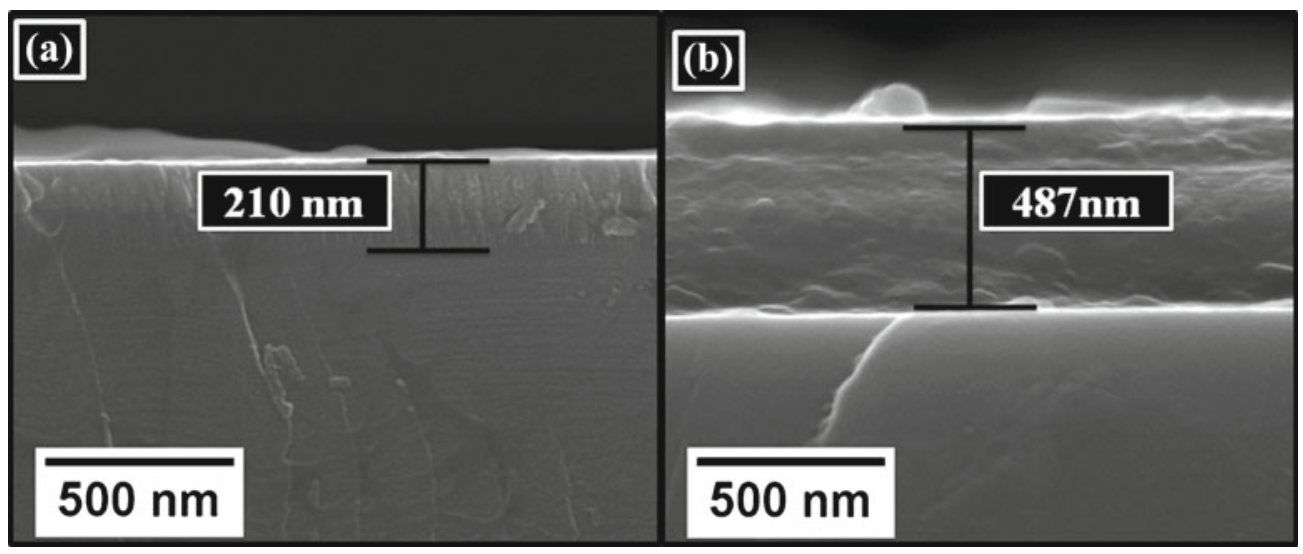

Figure 6. Cross-sectional FESEM images for (a) e-beam evaporated and (b) d.c. sputtered Ti films.

the bulk substrate material $\mathrm{Si}$ and the deposited Ti, and indicates that the film is composed of Ti metal only. Figure 6(a and b) shows cross-sectional images of Ti films for e-beam and d.c. sputtered Ti films, respectively. From figure 6(a), it is clear that the films are dense and exhibit columnar structures with a thickness of $\sim 210 \mathrm{~nm}$. Figure $6(\mathrm{~b})$ reveals that $\mathrm{Ti}$ films have a granular structure with a thickness of $\sim 487 \mathrm{~nm}$. As investigated from film thickness, Ti film deposited from e-beam is thinner than the film deposited using d.c. sputtering. It also revealed that the fcc could be stabilized for thin Ti film, whereas, hcp was stable over thicker films (Chakraborty et al 2011). Hence, the results obtained by FESEM and EDX are also in good agreement with the XRD and XPS results.

AFM was used to study the surface topography of Ti film. Figure 7(a and c) shows 2D AFM images and figure 7(b and d) depicts the corresponding 3D images for Ti films deposited using e-beam and d.c. sputtering, respectively. It is clear from figure $7(\mathrm{a}$ and $\mathrm{c})$ that the films are smooth with uniform distribution of fine grains over surface of the film. The root mean square (rms) surface roughness of the films was $\sim 2.3 \mathrm{~nm}$ and $\sim 4.9 \mathrm{~nm}$ for the two Ti films deposited using e-beam and d.c. sputtering techniques, respectively. The 


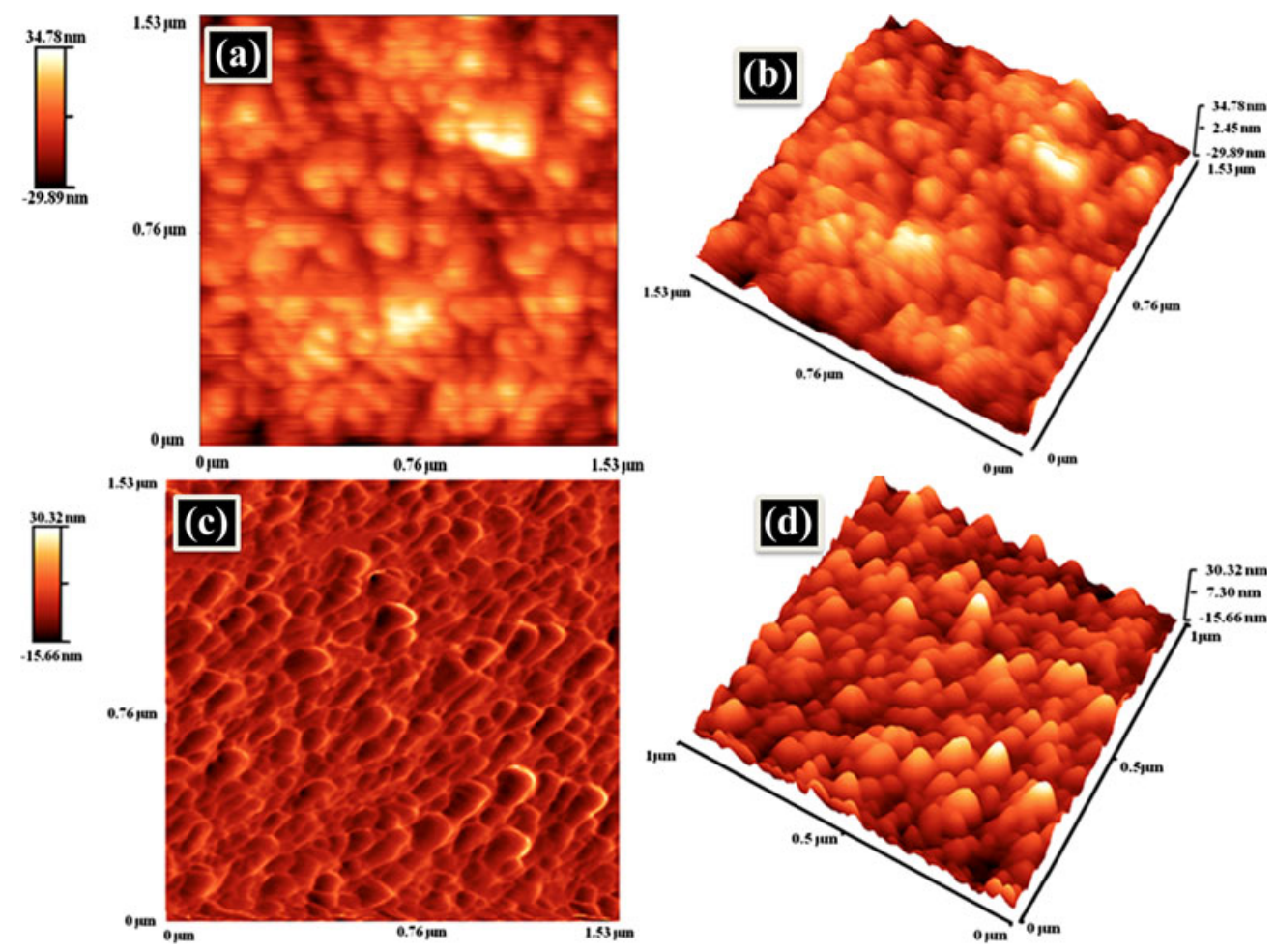

Figure 7. (a) $2 \mathrm{D}$ and (c) $3 \mathrm{D}$ preview of AFM images for e-beam evaporated and (b) $2 \mathrm{D}$ and (d) $3 \mathrm{D}$ preview of AFM images for d.c. sputtered Ti film.

average grain size of the films measured from AFM images are found to be in good agreement with the size obtained using XRD and FESEM.

The microhardness of Ti films deposited onto $\mathrm{Si} / \mathrm{SiO}_{2}$ (100) substrate using e-beam and d.c. sputtering techniques was measured using commercially available Vickers hardness tester. The load of the indenter was chosen in earlier report to limit the penetration depth to less than one tenth of film thickness (Standard ASTME 92 1986) in order to minimize the effect of substrate on hardness of the film. However, in the present work, the indenter penetration depth was always more than the film thickness. The film hardness was separated from the composite hardness of the filmsubstrate system by the use of an approach based on an area law-of-mixtures model (Jonsson and Hogmark 1984) to avoid the indentation size effect. In the framework of this approach, reasonable values of the intrinsic film hardness are obtained.

The hardness of the film was found to be $\sim 9.4 \mathrm{GPa}$ for e-beam deposited and $\sim 7.9 \mathrm{GPa}$ for d.c. sputtered film, respectively. Generally, the hardness of metal is known to be dependent on the crystallite size (Bendavid et al 1996). Bendavid et al (1996) reported that the microhardness varies linearly with inverse square root of the grain diameter in accordance to the Hall-Petch relationship (Petch 1954). It has also been reported earlier (Song et al 2007) that films with less thickness have more hardness than thicker films. Generally, for a smooth surface, Ti prefers (100) orientation. Also, hardness of Ti film with a (100) direction is higher than that of Ti film with a (002) direction (Song et al 2007). In the present report, Ti film deposited using d.c. sputtering having large grain size $(80 \mathrm{~nm})$ and $(002)$ preferred orientation has low value of hardness $(\sim 7.9 \mathrm{GPa})$, while the Ti film deposited by e-beam evaporation technique with small grain size $(25 \mathrm{~nm})$ and $(200)$ preferred orientation has high value of hardeness ( 9.4 GPa). Similar values of hardness for Ti films were also reported by various researchers. Bendavid et al (1996) observed that the Ti films deposited by filtered arc deposition showed a decrease in hardness value from $8.7 \mathrm{GPa}$ at $0 \mathrm{~V}$ substrate bias to $6.7 \mathrm{GPa}$ at $-250 \mathrm{~V}$ substrate bias. Additionally, Song et al (2007) reported that the hardness value of Ti films on a Si substrate was 6.8 GPa fabricated by using RF magnetron sputtering. Thus, the results obtained in the present study are reliable and in good agreement with the earlier reports (Bendavid et al 1996; Song et al 2007).

The electrical resistivity of a material is mainly determined by the intrinsic properties, defects and temperature (thermal vibrations). The electrical resistivity for Ti film was found to be $\sim 60 \mu \Omega \mathrm{cm}$ and $\sim 13 \mu \Omega \mathrm{cm}$ for e-beam evaporated and d.c. sputtered film, respectively. It has been reported earlier that the resistivity of Ti films increases with the decrease in thickness and also increase in grain size (Singh and Surplice 1972; Day et al 1995; Hofmann et al 2003). The observed difference in resistivity in the present report can be explained on the basis of thickness and grain size of the films. The film having high resistivity $(\sim 60 \mu \Omega \mathrm{cm})$ has low film thickness $(210 \mathrm{~nm})$ and small grain size $(\sim 25 \mathrm{~nm})$ and the film 
with low resistivity $(\sim 13 \mu \Omega \mathrm{cm})$ has large film thickness $(487 \mathrm{~nm})$ and grain size $(\sim 80 \mathrm{~nm})$.

\section{Conclusions}

In summary, Ti film has been successfully deposited using ebeam evaporation and d.c. sputtering technique and its structural, morphological, mechanical and electrical properties were studied. XRD results revealed the film deposited by e-beam evaporation technique possessed fcc symmetry with (200) preferred orientation, having a lattice parameter $a=$ $4.05 \AA$ and grain size of $\sim 25 \mathrm{~nm}$. While, XRD spectra of d.c. sputtered film show hcp symmetry with (002) preferred orientation having a lattice parameter $a=2.950 \AA, c=$ $4.681 \AA$ and grain size of $\sim 80 \mathrm{~nm}$. This difference in crystal structure and grain size is due to the difference in deposition rates and thickness of the film. The presence of metallic Ti phases in the film was also confirmed from XPS analysis. Ti $2 p$ doublet centred at $453.9 \mathrm{eV}$ and $460 \mathrm{eV}$ were observed in the core level spectra of $\mathrm{Ti}$ films and no secondary phase was observed on surface of the film. FESEM images revealed that the deposited film has fine grains and a thickness of $\sim 210 \mathrm{~nm}$ with columnar structure for e-beam evaporated sample. However, d.c. sputtered film has comparatively larger grains with a thickness of $\sim 487 \mathrm{~nm}$. AFM images revealed that the roughness of Ti films was $\sim 2.3 \mathrm{~nm}$ and $\sim 4.9 \mathrm{~nm}$ deposited using e-beam and d.c. sputtering technique. The hardness was found to be $\sim 9.4 \mathrm{GPa}$ for e-beam deposited film and $\sim 7.9 \mathrm{GPa}$ for d.c. sputtered film. This difference in hardness of the Ti films is due to the difference in thickness and preferred orientation of the films. The electrical resistivity was found to be $\sim 60 \mu \Omega \mathrm{cm}$ for e-beam evaporated Ti films due to low thickness and smaller grain size, while $\sim 13 \mu \Omega \mathrm{cm}$ for d.c. sputtered Ti films due to larger thickness and larger grain size.

\section{Acknowledgements}

This research was supported by Basic Science Research Program through the National Research Foundation of Korea (NRF), funded by the Ministry of Education, Science and Technology (2010-0021715). This work was also supported by research funds of Changwon National University in 2011.

\section{References}

Benard W L, Kahn H, Heuer A H and Huff M A 1998 J. Microelectromech. Syst. 7245
Bendavid A, Martin P J, Smith G B, Wielunski L and Kinder T J 1996 Vacuum 471179

Boyer R R 1996 Mater. Sci. Eng. A213 103

Bunshah R F and Juntz R S 1973 Metall. Trans. 421

Cai K, Muller M, Bossert J, Rechtenbach A and Jandt K D 2005 Appl. Surf. Sci. 250252

Chakraborty J, Kumar K, Ranjan R, Chowdhury S G and Singh S R 2011 Acta Mater. 592615

Chawla V, Jayaganthan R, Chawla A K and Chandra R 2009 J. Mater. Proces. Technol. 2093444

Day M E, Delfino M, Fair J A and Tsai W 1995 Thin Solid Films 254285

Galvanettoa E, Gallianoa F P, Borgiolia F, Bardib U and Lavacchi A 2001 Thin Solid Films 384223

Henderson P S, Kelly P J, Amell R D, Backer H and Bradley J W 2003 Surf. Coat. Technol. 174-175 779

Hofmann K, Spangenberg B, Luysberg M and Kurz H 2003 Thin Solid Films 436168

Hyun S, Brown W L and Vinci R P 2004 Proc. SPIE 5343154

Jeyachandran Y L, Karunagaran B, Narayandass S K, Mangalaraj D, Jenkins T E and Martin P J 2006 Mater. Sci. Eng. A431 277

Jeyachandran Y L, Narayandass S K, Mangalaraj D, Sami Areva J A and Mielczarski 2007a Mater. Sci. Eng. A445-446 223

Jeyachandran Y L, Karunagaran B, Narayandass S K and Mangalaraj D 2007b Mater. Sci. Eng. A458 361

Jonsson B and Hogmark S 1984 Thin Solid Films 114257

Kajikawa Y, Noda S and Komiyama H 2002 Chem. Vapor Depos. 8 99

Kim S K, Marcus P M and Jona F 1996 J. Phys. Condens. Matter 825

Manna I, Chattopadhyay P P, Nandi P and Banhart F 2003 J. Appl. Phys. 931520

Martin N, Baretti D, Rousselot C and Rauch J Y 1998 Surf. Coat. Technol. 107172

Muraishi S, Aizawa T and Kuwahara H 2004 Surf. Coat. Technol. 188-189 260

Naoe M, Ono S and Hirata T 1991 Mater. Sci. Eng. A134 1292

Petch N J 1954 Prog. Met. Phys. 51

Resnik D, Kovac J, Vrtacnik D, Aljancic U, Mozek M, Zalar A and Amon S 2008 Vacuum 82162

Salch A A, Shutthanandan V, Shivaparan N R, Smith R J, Tran T T and Chambers S A 1997 Phys. Rev. B56 9841

Scardi P, Leoni M and Checchetto R 1998 Mater. Lett. 361

Singh B and Surplice N A 1972 Thin Solid Films 10243

Song Y H, Cho S J, Jung C K, Bae I S and Boo J H 2007 J. Korean Phys. Soc. 511152

Standard ASTME 921986 Annual book of standards 3.01 (Philadelphia, PA: American Society for Testing and Materials) p. 72

Warren B E 1969 X-ray diffraction (London: Addison Wesley Publishing Co.) p. 18

Wayman C M 1992 Prog. Mater. Sci. 36203

Wei Z G, Sandstorm R and Miyazaki S 1998 J. Mater. Sci. 33 3743 